\title{
DIREITO DO RECONHECIMENTO E DA LIBERTAÇÃO: novas perspectivas do método jurídico na produção do Direito
}

Luciano Gomes dos Santos ${ }^{1}$

Resumo: O objetivo do presente artigo é analisar o direito como reconhecimento e libertação. Busca-se novas perspectivas do método jurídico na produção do direito. Apresenta-se a tese de base conceitual e teórica do direito, ou seja, teoria e aplicação do direito. Os fundamentos do direito como reconhecimento e libertação inspiram-se na teoria do reconhecimento de Axel Honneth e na Teologia da Libertação. O direito enquanto reconhecimento fundamenta-se nas esferas do amor, direito e solidariedade. Na perspectiva da libertação, o direito baseia no método "Ver-julgar-Agir", ou seja, ver a realidade do sujeito, julgar a realidade à luz do direito e agir para transformar a condição de não reconhecimento para o reconhecimento intersubjetivo.

Palavras-chaves: Direito. Reconhecimento. Libertação. Método Jurídico. Produção Jurídica.

\section{RIGHT OF RECOGNITION AND LIBERATION: new perspectives of the legal method in the production of Law}

Abstract: The aim of this article is to analyze the law as recognition and liberation. It seeks new perspectives of the legal method in the production of law. The thesis is based on conceptual and theoretical theory, ie theory and application of law. The foundations of law as recognition and liberation are inspired by Axel Honneth's Theory of Recognition and Liberation Theology. Right as recognition is based on the spheres of love, law and solidarity. In the perspective of liberation, the right is based on the "See-judge-Act" method, that is, to see the reality of the subject, to judge reality in the light of law and to act to transform the condition of nonrecognition to intersubjective recognition.

Keywords: Right. Recognition. Release. Legal Method. Legal Production.

\section{Introdução}

O objetivo do presente artigo visa apresentar uma proposta de metodologia jurídica $-o$ direito do reconhecimento e da libertação. A produção do direito requer metodologia adequada para atender as demandas da sociedade contemporânea frente à diversidade de conflitos sociais.

\footnotetext{
${ }^{1}$ Doutorando no Programa de Pós-graduação em Direito pela PUC Minas e doutorando no Programa de Pósgraduação em Teologia pela FAJE - Belo Horizonte/MG. Professor da Faculdade de Direito Padre Arnaldo Janssen e no Colégio/Faculdade Cotemig - MG. E-mail: luguago@ig.com.br
} 
As teorias abrangentes do direito implicam duas questões: o conceito e a aplicação do direito. Em outras palavras, "a aplicação do direito depende de como se conceitua o direito e, por outro lado, o conceito de direito depende do modo como se encara a aplicação do direito" (TRIVISONNO, 2015, p.01).

O direito como reconhecimento e libertação visa contribuir com a Teoria do Direito. Historicamente, a modernidade em sua categoria de racionalidade não conseguiu cumprir com os ideais de esclarecimento e emancipação do ser humano. A racionalidade moderna tardia foi utilizada de forma ampla para dominar e oprimir consciências. O método positivista conjugado com o desenvolvimento da sociedade capitalista "conseguiu assentar doutrinas e técnicas de simplificação e otimização da organização política societal, gerando entraves ao cumprimento da justiça e da ética" (GONTIJO, 2011, p.65). Entendemos que ocorreu o descarte da justiça e da ética.

Identificamos que o esforço do direito nos últimos séculos afastou "a complexidade sociológica e a subjetividade antropológica tornando-se um aparato abstrato, formal, mas assaz eficiente para os fins a que se presta: assentar relações de poder" (GONTIJO, 2011, p.65). Investiga-se a possibilidade de um método como processo de humanização do direito, visando reconhecimento e a libertação do sujeito em sua humilhação pessoal e social.

A proposta do método se assenta na Teoria do Reconhecimento (TdR) de Axel Honneth e na Teologia da Libertação (TdL) de Gustavo Gutiérrez. As duas teorias contribuem com o aspecto teórico e prático. A TdR defende a tese de que o ser humano possui sua identidade pessoal e social reconhecida por meio de três esferas: amor, direito e solidariedade. O reconhecimento se dá por meio de lutas por reconhecimento, quando o sujeito toma consciência de sua humilhação social e reificação de seu ser.

A TdL desenvolveu-se na América Latina no final da década de 1960, como resposta à realidade dos pobres não reconhecidos e oprimidos pelos sistemas políticos e econômicos. É uma reflexão teológica crítica que nasce a partir do sofrimento da alteridade. A TdL buscou libertar o discurso teológico abstrato/formal distante da realidade do povo; e, libertar o pobre oprimido e destituído de seu reconhecimento pessoal e social. Adotou-se o método "Ver-julgarAgir", baseado em três mediações: sócio-analítica, hermenêutica e teórico-práxis. Optou-se preferencialmente pelo pobre oprimido. 
É a partir das referidas teorias filosófica e teológica que desenvolveremos a proposta do método jurídico como reconhecimento e libertação na produção do direito. O estudo está dividido em quatro partes: (1) Método e metodologia jurídica: perspectivas teóricas; (2) Teoria do Reconhecimento (TdR); (3) Teologia da Libertação (TdL); (4) Direito: Reconhecimento e Libertação.

\section{Método e metodologia jurídica: perspectivas teóricas}

O direito requer conhecimentos e técnicas específicas para sua efetivação. O Direito é uma Ciência Social Aplicada. A reflexão sobre o método jurídico apresenta dois aspectos: (1) elaboração de uma teoria do direito que possibilite o conhecimento ao fenômeno jurídico e sua explicação; (2) a constituição de uma dogmática do direito contribuindo para a solução de questões jurídica (OLIVEIRA, 2013, p. 97). Na primeira dimensão, busca-se a efetivação de uma ciência do direito. Na segunda dimensão, a intencionalidade do jurista visa à solução de questões jurídicas.

A palavra método, etimologicamente, é de origem grega e significa "o caminho pelo qual sigo uma coisa” (HEIDEGGER, 2003, p.47). A partir da influência do filósofo René Descartes, "método é um termo que remete à ideia de certeza e segurança do conhecimento que se obtém através do emprego de certas estratégias de pensamento" (OLIVEIRA, 2013, p. 98). Entende-se que o método é mediação para se chegar a um resultado. Deve-se ter consciência de que o método pode incorrer em certas falhas e ser passível de revisão e adaptação aos novos desafios.

Entende-se que sem uma metodologia rigorosa, não se podem conceber regras capazes de reger eficazmente e com total segurança a realidade social, nem aplicar soluções jurídicas apropriadas à infinidade de situações de fato. Toda elaboração jurídica é dominada por operações intelectuais e por uma metodologia, baseadas ambas nos princípios da lógica comum, com certa flexibilização comandada pela natureza peculiar do objeto por examinar: as regras jurídicas.

A metodologia jurídica, ciência dos métodos do direito, define-se como o estudo das técnicas empregadas pelos juristas: legisladores, juízes, advogados, acadêmicos, etc. Mas 
também é o estudo das diversas técnicas jurídicas que variam conforme as atividades consideradas: elaboração e redação de textos, estudo do direito, aplicação do sistema jurídico. Perspectivas, objetivos, meios e métodos não são evidentemente os mesmos quando o objetivo é elaborar a lei, proferir um julgamento, negociar um contato e ensinar, expor ou aprender o direito.

O conhecimento e a aplicação dos métodos jurídicos são imprescindíveis. São eles indispensáveis à determinação e à expressão das regras de direito pelo legislador, à sua interpretação, à solução dos litígios, à argumentação das partes no processo, à negociação e ao estabelecimento dos contratos pelos advogados, à formação eficaz dos estudantes etc. A todos é necessário o estudo dos procedimentos do direito, dos mecanismos intelectuais dos juristas, das formas de raciocínio às quais eles recorrem, dos procedimentos técnicos que empregam. Mas essa exigência de metodologia jurídica não pode ser atendida a ponto de perverter ou deformar abusivamente os fatos ou os valores essenciais: é preciso vencer o risco da abstração e do desconhecimento das realidades acarretados pela redução do direito a operações lógicas.

Uma metodologia jurídica deve ser aceitável, praticável e eficaz. Sabe-se que "o direito deve constituir um conjunto coerente de elementos interdependentes, ou seja, um sistema" (ALLAND; RIALS, 2012, p.1183). A própria noção de metodologia jurídica está ligada à ideia de construção racional do direito e à ideia de sistema jurídico. Com isso se deve entender o conjunto estruturado, organizado e interdependente das regras e dos mecanismos jurídicos que se aplicam numa sociedade.

A concepção de sistema é utilizada para dar conta da complexidade e da diversidade da ordem jurídica, bem como das interações entre instituições e normas que ele implica, sem que se deixem de lado as exigências da realidade social e os fatos que o direito tem vocação para tratar. O sistema jurídico se caracteriza tanto pelos elementos que o compõem quanto pelas interações entre estes - o que se pode ser sintetizado pela fórmula "tudo é coeso" -, pode-se ver nele "um conjunto de práticas, métodos e instituições que formam, ao mesmo tempo, um arcabouço teórico e um método prático" (ALLAND; RIALS, 2012, p.1184).

Essa compreensão do direito como sistema pode coincidir com sua abordagem "analítica", que consiste em explicar termos, conceitos e estruturas jurídicas, bem como em mostrar como o todo é entendido como ordenamento coerente dos elementos que o compõem. Por outro lado, a análise do direito como "sistema aberto" não exclui as influências do meio 
social, econômico, político e filosófico sobre o sistema jurídico; alguns estudiosos defendem que o direito não passa de subsistema do sistema social global.

A definição do direito como sistema ou mesmo como subsistema que comportaria múltiplos subconjuntos em interação é perfeitamente compatível com uma abordagem axiológica, quaisquer que sejam os valores considerados. A consideração de valores morais e sociais integra-se numa análise "sistêmica", uma vez que o sistema é "aberto" e pode tratar-se de um "conjunto difuso", dialógico, que comporta até normas "difusas", que permitem a seus destinatários grande liberdade de descodificação.

A concepção do direito como "sistema flexibilizado" não se reduz a um conjunto formal, rígido e abstrato, como no modelo puramente normativo e hierarquizado de Hans Kelsen. Com tal "sistematização externa", o direito é integrado "na sociedade, está em constante evolução, e também se integra no sistema de valores e de normas que domina essa sociedade" (ALLAND; RIALS, 2012, p.1184). Exemplificando, a lei deve ser interpretada no sentido de ser compatível com o sistema jurídico da qual depende, e não no sentido de estar em contradição com ele. Sua interpretação deve conformar-se ao espírito do legislador e às finalidades buscadas ou aos valores consagrados. Também deve ser fiel ao texto para respeitar a lógica das instituições.

A sistematização do direito possibilita alijá-lo de contradições, segundo métodos de interpretação "sistêmica" e princípios de solução dos conflitos de leis, bem como preencher suas lacunas graças a princípios gerais e a procedimentos lógicos, como a analogia ou o argumento a fortiori. Alguns teóricos associam a dogmática e a metodologia jurídica ao positivismo jurídico. A sistematização e a interpretação das regras de direito e a eliminação de suas contradições e de lacunas se limitariam à esfera estrita do direito em vigor e excluiriam qualquer "ciência do direito". Há nessa perspectiva uma desnaturação da análise do direito como sistema aberto e complexo e da metodologia jurídica, que pode absorver todos os valores consagrados numa sociedade.

Admite-se o princípio da neutralidade da metodologia jurídica, que não está associada a nenhuma escola determinada de pensamento. Ela tem lugar em todas as concepções que rejeitam a improvisação e a irracionalidade do direito. Método é uma maneira de orientar o pensamento, e a metodologia jurídica é o estudo dos procedimentos e dos métodos que os 
juristas praticam em suas atividades de pesquisa, criação e aplicação do direito e, mais geralmente, para chegar à solução dos problemas jurídicos.

A "metodologia jurídica está ligada tanto à técnica quanto à ciência do direito" (ALLAND; RIALS, 2012, p.1185). Compreendemos que a metodologia jurídica está intrinsecamente associada à teoria geral do direito, que estuda a ordem jurídica em sua globalidade, a partir da observação dos diversos sistemas jurídicos, empenhando-se em definir os grandes eixos de construção e aplicação do direito. A metodologia jurídica é apenas uma parte dela e só diz respeito às vias e aos meios utilizados nas diversas ações de exploração, criação e aplicação direito.

Entendemos que a objeto fundamental da metodologia jurídica parecer ser estabelecer e aplicar soluções de direito a situações de fato, garantindo a "exequibilidade do direito" (ALLAND; RIALS, 2012, p.1185). O trabalho dos juristas é constante movimento dialético entre o fato e o direito. Consiste sempre em aplicar o direito existente a fatos ou em imaginar novas soluções jurídicas apropriadas para regê-los. É com essa finalidade que os juristas utilizam métodos específicos para aproximar direito e fato, por meio da qualificação dos fatos ou do silogismo jurídico.

Compreendemos que há diversos métodos jurídicos ${ }^{2}$ que foram emergindo no desenvolvimento do direito. O método jurídico implica a construção uma "Ciência do Direito" e uma dogmática do direito enquanto soluções de conflitos. Destacamos a importância da teoria abrangente do direito: teoria e práxis. A construção do conceito de direito e os procedimentos para sua práxis.

O século XX no âmbito do direito tornou-se o século de Hans Kelsen na construção da "Ciência do Direito". O jurista é exemplo de esforço na elaboração de uma "Ciência do Direito". Sabemos que "as marcas definitivas deixadas por Kelsen no pensamento jurídico são reconhecidas e assinaladas por grandes nomes da doutrina jurídica dos mais diversos matizes filosóficos" (AFONSO, 2013, p. 39). Entendemos que "o grande tributo que a doutrina jurídica tem prestado a kelsen é o de reconhecer o seu esforço para a consolidação ou mesmo a construção definitiva da ciência do direito" (AFONSO, 1984, p. 201). A doutrina "Pura do Direito", proposta por Kelsen, revela o método de se fazer direito como sistema científico.

\footnotetext{
${ }^{2}$ Teoria Pura do Direito de Hans Kelsen; Teoria da razoabilidade, da prática e do valor de Chaïm Perelman; Teoria do direito como auto-referencial de Niklas Luhmann.
} 
Quando Hans Kelsen designa sua teoria do direito, como "pura", "isto significa que ela se propõe garantir um conhecimento apenas dirigido ao Direito e excluir deste conhecimento tudo quanto não pertence ao seu objeto, tudo quanto não se possa, rigorosamente, determinar como Direito" (KELSEN, 1985, p. 01). O seu objetivo era desenvolver uma Ciência Jurídica liberta de quaisquer elementos estranhos. A Ciência Jurídica desenvolvida ao longo dos séculos XIX e XX estava distante de satisfazer à exigência da pureza. Por isso, Kelsen aponta que de um lado "inteiramente acrítico, a jurisprudência tem-se confundido com a psicologia e a sociologia, com a ética e a teoria política" (KELSEN, 1985, p. 01). A confusão entre direito e as ciências citadas, ocorre devido à estreita relação de estudo entre os mesmos objetos. Por isso, a Teoria Pura empreende delimitar o conhecimento do Direito em face destas
disciplinas, fá-lo não por ignorar ou, muito menos, por negar essa conexão, mas
porque intenta evitar um sincretismo metodológico que obscurece a essência da
ciência e dilui os limites que lhe são impostos pela natureza do seu objeto (KELSEN,
1985, p. 01).

Percebemos no pensamento de Kelsen, que ele não nega que o direito possa ser objeto de outras ciências, "mas delimita o conhecimento jurídico em face delas para evitar um sincretismo metodológico que obscurece a essência da ciência jurídica e dilui os limites que lhe são impostos pela natureza do seu objeto" (GOMES, 2004, p.185-186). Nessa perspectiva, constata Bodenheimer: "A teoria pura do direito é uma tentativa de banir da ciência do direito todos os elementos não-jurídicos. Direito e Estado deve ser entendidos como realidades puramente jurídicas, e outras disciplinas como a psicologia, sociologia e a ética devem ser banidas da ciência jurídica” (BODENHEIMER apud GOMES, 2004, p. 185 - 186). Kelsen possui duplo objetivo: "afastar da Ciência do Direito quaisquer valorações ético-políticas e, ainda, evitar as influências sociológicas que não separavam o direito dos fatos sociais" (GOMES, 2004, p.186-187).

Há na obra de Kelsen, a distinção fundamental entre ser e dever-ser. "Este corresponde ao mundo da normatividade, enquanto aquele ao mundo dos fatos" (GOMES, 1997, p.108). Por isso, "o objeto da ciência jurídica é o conjunto de normas de uma ordem jurídica que regulam a conduta humana, não sendo, pois, como a sociologia, uma ciência dos fatos" (GOMES, 1997, 
p.108). Assim, "a ciência jurídica descreve seu objeto por meio da proposição jurídica" (GOMES, 1997, p.108). Kelsen afirma que,

\begin{abstract}
na medida em que a ciência jurídica apenas apreende a conduta humana enquanto esta constitui conteúdo de normas jurídicas, isto é, enquanto é determinada por normas jurídicas, representa uma interpretação normativa destes fatos de conduta. Descreve as normas jurídicas produzidas através de atos de conduta humana e que hão de ser aplicadas e observadas também por atos de conduta e, consequentemente, descreve as relações construídas, através dessas normas jurídicas, entre os fatos por elas determinados. As proposições ou enunciados nos quais a ciência jurídica descreve estas relações devem, como proposições jurídicas, ser distinguidas das normas jurídicas que são produzidas pelos órgãos jurídicos a fim de por eles serem aplicadas e serem observadas pelos destinatários do Direito (KELSEN, 1985, p. 78).
\end{abstract}

Afirmamos que "a função da ciência jurídica é conhecer por fora, o Direito, e descrevêlo com base em seu conhecimento. Os órgãos jurídicos têm, como autoridade jurídica, a missão de produzir o Direito para que ele possa ser conhecido e descrito pela ciência jurídica" (GOMES, 1997, p.110). Segundo Kelsen, “o direito não é, contudo, uma norma, mas um sistema de normas. O caráter jurídico de uma norma dá-se por sua pertinência a um sistema de normas jurídicas conhecido como ordenamento jurídico" (KELSEN apud BARZOTTO, 2007, p. 34).

Kelsen estabeleceu uma teoria do conhecimento jurídico, na qual o jurídico possui recortes bem delimitados, traduzindo-se no Direito positivo. Destaca o direito posto e apresenta seus instrumentos teóricos. “A Teoria Pura do Direito se classifica como uma Ciência do Direito positivo e o Direito, definido como seu objeto, é conceituado como um sistema de normas" (AFONSO, 2013, p. 45). O caminho para efetivar a ciência do direito fundamentou-se no postulado metodológico da pureza. A categoria Pura refere-se a exclusão do seu campo de conhecimento tudo que não possa ser abarcado como Direito, que é o seu objeto de investigação.

A seguir, discorreremos sobre a Teoria do Reconhecimento e da Teologia da Libertação, visando propor teoria e método produção do direito.

\title{
2 Teoria do Reconhecimento (TdR)
}

A categoria reconhecimento vem ganhando espaço nos últimos vinte anos no debate filosófico, político, sociológico e jurídico. No universo cultural e linguístico alemão, fonte hegeliana das teorias contemporâneas do reconhecimento, o termo "Anerkennung" significa 
reconhecimento intersubjetivo ou recíproco. "O conceito fillosófico de reconhecimento não significa simplesmente a identificação cognitiva de uma pessoa, mas sim, tendo esse ato como premissa, a atribuição de um valor positivo a essa pessoa, algo próximo do que entendemos por respeito" (ASSY, 2006, p.705). A noção de reconhecimento implica dimensão axiológica e, portanto dignidade da pessoa.

No contexto do reconhecimento, compreendemos a relação entre subjetividade e intersubjetividade. Nelas, revela-se uma relação profícua entre individuo e comunidade, particularidade e universalidade, ou ainda entre diferença e identidade. Essas dicotomias são colocadas à prova quando se manifesta a experiência do reconhecimento:

\begin{abstract}
A partir da ideia de reconhecimento pode se desdobrar um conceito de intersubjetividade aonde formas diferentes de sociabilidade vão surgindo no decorrer dos próprios conflitos em torno do reconhecimento, nas quais as pessoas ao mesmo tempo afirmam sua subjetividade autônoma e reconhecem-se na sua pertença comunitária. Ou seja, a relação constitutiva entre identidade pessoal e a práxis cultural e as instituições é entendida não como relação instrumental ou relação de dependência orgânica, substantiva, do indivíduo com a comunidade, mas como relação reflexiva de reconhecimento recíproco. $\mathrm{O}$ reconhecimento permite uma reconciliação, sempre passível de revisão, quando for o caso, entre diferença e identidade (WERLE, 2004, p.52).
\end{abstract}

A categoria de reconhecimento implica relações intersubjetivas. As formas de diferentes sociabilidades surgem na decorrência dos próprios conflitos sociais em torno do reconhecimento tanto na afirmação da subjetividade autônoma quanto na pertença comunitária. O reconhecimento aparece como chave central que permite a reconciliação entre diferença e identidade.

A primeira constituição teórica da teoria do reconhecimento foi concebida pelo filósofo Hegel. Defendia relações práticas de intersubjetividade no intuito de lutar pela preservação da identidade moral do indivíduo. O jovem Hegel acreditava que a camada social é o espaço do mútuo reconhecimento entre os sujeitos tanto nas potencialidades quanto nas capacidades. $\mathrm{O}$ estímulo ao reconhecimento recíproco dos sujeitos possibilita lutarem juntos por novos níveis de reconhecimento na sociedade.

Axel Honneth assume a proposição hegeliana, em que a luta dos indivíduos pelo reconhecimento intersubjetivo de suas identidades promove "uma pressão intra-social para o 
estabelecimento prático e político das instituições garantidoras de liberdade" (HONNETH, 2003, p. 29). Há uma pretensão dos sujeitos ao reconhecimento intersubjetivo de sua identidade intrínseca à vida social. A luta por reconhecimento em Hegel é por impulsos morais.

Na perspectiva de Hegel, o reconhecimento se daria em três âmbitos das relações: 1) família; 2) direito (identificado com a sociedade civil) e 3) Eticidade (representada pelo Estado, que é definido por Hegel como o espírito do povo) - (HONNETH, 2003, p. 60). “O movimento de reconhecimento que subjaz a uma relação ética entre sujeitos consiste num processo de etapas de reconciliação e de conflito ao mesmo tempo, as quais substituem umas às outras" (HONNETH, 2003, p. 47). O conflito prático entre os sujeitos origina-se a partir do acontecimento ético, na medida em que objetiva o reconhecimento intersubjetivo das dimensões da individualidade humana.

A teoria do reconhecimento, na elaboração honnethiana, é uma atualização do pensamento do jovem Hegel no período de seus escritos em Iena e do psicólogo americano Georg H. Mead, que defende a "gênese social da identidade e vê a evolução moral da sociedade na luta por reconhecimento. Mead aprofunda o olhar intersubjetivista, defendendo a existência de um diálogo interno, e investiga a importância das normas morais nas relações humanas" (NETO, 2011, p.142). Entende-se que nas “interações sociais, ocorrem conflitos entre o 'eu' e a 'cultura' e os 'outros', por meio dos quais indivíduos e sociedade desenvolver-se-iam normalmente" (NETO, 2011, p.140).

A concepção de Mead é análoga à teoria do reconhecimento elaborada por Honneth desenvolvida em sua teoria crítica, que o reconhecimento passa por três tipos de relação: as primárias (guiadas pelo amor), as jurídicas (pautadas por leis) e a esfera do trabalho (na qual os indivíduos poderiam mostrar-se valiosos para a coletividade) - (NETO, 2011, p.142). É a partir dessa fundamentação que Honneth sistematizou sua teoria do reconhecimento intersubjetivo, como base da formação da identidade do sujeito. "São as lutas moralmente motivadas de grupos sociais, sua tentativa de estabelecer institucional e culturalmente formas ampliadas de reconhecimento recíproco, aquilo por meio do qual vem a se realizar a transformação normativamente gerida das sociedades" (HONNETH, 2003, p. 156).

Axel Honneth atualiza os argumentos de Hegel e de Mead, extraindo deles as três esferas do reconhecimento intersubjetivo: as ligações emotivas fortes; a adjudicação de direitos e a orientação por valores. Na obra Luta por Reconhecimento - a gramática moral dos 
conflitos sociais, o autor estabelece os fundamentos de sua teoria do reconhecimento intersubjetivo. Segundo o autor, a sociedade deve ser interpretada a partir da categoria do reconhecimento. Abaixo segue o quadro que sintetiza as dimensões da Teoria do Reconhecimento (HONNETH, 2003, p. 211):

\begin{tabular}{|c|c|c|c|}
\hline $\begin{array}{l}\text { Modos de } \\
\text { reconhecimento }\end{array}$ & Dedicação emotiva & Respeito cognitivo & Estima social \\
\hline $\begin{array}{l}\text { Dimensões da } \\
\text { personalidade }\end{array}$ & $\begin{array}{c}\text { Natureza carencial e } \\
\text { afetiva }\end{array}$ & $\begin{array}{c}\text { Imputabilidade } \\
\text { moral }\end{array}$ & $\begin{array}{l}\text { Capacidades e } \\
\text { propriedades }\end{array}$ \\
\hline $\begin{array}{l}\text { Formas de } \\
\text { reconhecimento }\end{array}$ & $\begin{array}{l}\text { Relações primárias } \\
\text { (amor, amizade) }\end{array}$ & $\begin{array}{l}\text { Relações jurídicas } \\
\text { (direitos) }\end{array}$ & $\begin{array}{c}\text { Comunidade de } \\
\text { valores } \\
\text { (solidariedade) }\end{array}$ \\
\hline Potencial evolutivo & & $\begin{array}{l}\text { Generalização, } \\
\text { materialização }\end{array}$ & $\begin{array}{l}\text { Individualização, } \\
\text { igualização }\end{array}$ \\
\hline $\begin{array}{l}\text { Autorrelação } \\
\text { prática }\end{array}$ & Autoconfiança & Autorrespeito & Autoestima \\
\hline $\begin{array}{l}\text { Formas de } \\
\text { desrespeito }\end{array}$ & $\begin{array}{l}\text { Maus-tratos e } \\
\text { violação }\end{array}$ & $\begin{array}{l}\text { Privação de direitos } \\
\text { e exclusão }\end{array}$ & Degradação e ofensa \\
\hline $\begin{array}{l}\text { Componentes } \\
\text { ameaçados da } \\
\text { personalidade }\end{array}$ & Integridade física & Integridade social & "Honra", dignidade \\
\hline
\end{tabular}

Axel Honneth apresenta três formas de reconhecimento e três formas de desrespeito. As três formas de reconhecimento são: relações primárias (amor, amizade), relações jurídicas (direito) e a comunidade de valores (solidariedade). O reconhecimento do amor "é o núcleo fundamental de toda a moralidade [...] este tipo de reconhecimento é responsável não só pelo desenvolvimento do auto-respeito, mas também pela base de autonomia necessária para a participação na vida pública” (SAAVEDRA; SOBOTTAKA, 2008, p.11).

Segundo Axel Honneth, no amor o reconhecimento afetivo possibilita ao indivíduo adquirir confiança em si mesmo e autoconfiança nas relações eróticas entre dois parceiros, nas de amizades e entre pais e filhos. A autoconfiança individual é entendida como a base 
indispensável para a participação autônoma na vida pública. No entanto, violações e maustratos afetam a integridade física e a autoconfiança. Formas de desrespeito que afetam a integridade corporal não são lesivas somente "pela dor puramente corporal, mas por sua ligação como sentimento de estar sujeito à vontade de um outro, sem proteção, chegando à perda do senso de realidade" (HONNETH, 2003, p. 215). O sujeito perde a confiança em si e no mundo, somada com uma vergonha social que impede a existência de uma autorrelação positiva.

O reconhecimento jurídico "contempla não só as capacidades abstratas de orientação moral, mas também as capacidades concretas para uma existência digna [...] a esfera do reconhecimento jurídico cria as condições que permitem ao sujeito desenvolver autorrespeito" (SAAVEDRA; SOBOTTAKA, 2008, p.12). No direito o reconhecimento jurídico permite que o sujeito adquira autorrespeito por perceber-se reconhecido como membro de uma sociedade e protegido por determinados direitos. Mas para isso, devemos compreender que nos percebemos como portadores de direitos, no momento em que sabemos, quais obrigações temos com relação aos outros. $\mathrm{O}$ autorrespeito está presente em um indivíduo no momento em que ele pode constatar que goza do respeito de todos os parceiros de interação e a negação de direitos e a exclusão geram experiências de rebaixamentos.

Por isso, a particularidade nas formas de desrespeito, como as existentes na privação de direitos ou na exclusão social, não representa somente a limitação violenta da autonomia pessoal, mas também sua associação como o sentimento de não possuir o status de um parceiro de interação com igual valor, moralmente em pé de igualdade (HONNETH, 2003, p. 216).

Junto à experiência de privação de direitos surge a perda de autorrespeito, ou seja, a perda da possibilidade de se autoperceber com capacidades suficientes para se referir em pé de igualdade com todos os próximos.

A terceira forma de reconhecimento se refere à comunidade de valores ou solidariedade. Nesta esfera, destacam-se as propriedades diferenciais dos seres humanos de forma genérica, vinculativa e intersubjetiva (HONNETH, 2003, p. 216). Encontramos também o nível da integração social a partir dos "valores e objetivos que funcionam como um sistema de referência para a avaliação moral das propriedades pessoais dos seres humanos e cuja totalidade constitui a autocompreensão cultural de uma sociedade" (SAAVEDRA; SOBOTTAKA, 2008, p.13). 
Nesta esfera, os indivíduos estão integrados numa comunidade de vida e só podem ser avaliados intersubjetivamente.

Na solidariedade o reconhecimento social possibilita que o sujeito adquira autoestima, que se perceba como possuidor de determinadas habilidades e talentos valiosos para a sociedade e se sinta autorrealizado. Os critérios para avaliar a estima social variam de acordo com a cultura e com o período histórico, visto que estes são determinados de forma intersubjetiva. A solidariedade é entendida como uma espécie de relação interativa em que os sujeitos, por se estimarem entre si, se interessam mutuamente por seus modos distintos de vida. "Estimar-se simetricamente nesse sentido significa considerar-se reciprocamente à luz de valores que fazem as capacidades e as propriedades do respectivo outro aparecer como significativas para a práxis comum" (HONNETH, 2003, p. 210).

Axel Honneth apresenta três formas de desrespeito: (1) maus tratos e violação, atingindo a integridade física da pessoa; (2) privação de direito e exclusão, afetando a integridade social; por fim, (3) degradação e ofensa, ameaçando a honra e a dignidade do indivíduo. Por isso, a luta pelo reconhecimento sempre inicia pela experiência do desrespeito à dignidade do sujeito. A autorrealização do indivíduo somente é alcançada quando há, na experiência de amor, a possibilidade de autoconfiança, na experiência de direito, o autorrespeito e, na experiência de solidariedade, a autoestima.

$\mathrm{Na}$ obra Luta por reconhecimento: a gramática moral dos conflitos sociais, Axel Honneth afirma que o reconhecimento é uma condição para que os indivíduos desenvolvam suas relações práticas, buscando a autorrealização e, consequentemente, adquiram sua autonomia. Nessa perspectiva, "os diversos padrões de reconhecimento representam condições intersubjetivas que temos de pensar necessariamente quando queremos descrever as estruturas universais de uma vida bem-sucedida” (HONNETH, 2003, p. 273).

Axel Honneth em Luta por reconhecimento concebe a integração social, nessa etapa da sua obra, não apenas em termos econômicos ou em relação à aquisição de direitos formais; mas em termos de reconhecimento. O indivíduo busca reconhecimento de diferentes porções de sua personalidade e, desse modo, vai desenvolvendo simultaneamente a sua identidade e relações práticas. Todavia, o reconhecimento está ancorado em uma relação intersubjetiva, que se define 
entre parceiros de interação. Disso decorre que existe a possibilidade de não-reconhecimento e, portanto, de desrespeito.

As experiências de desrespeito são a chave interpretativa utilizada por Honneth para construir a gramática moral dos conflitos sociais. Há um entendimento de que o desrespeito priva as pessoas de sua liberdade de ação e, ao mesmo tempo, interfere negativamente na compreensão que as pessoas têm de si próprias. Assim, as experiências de desrespeito desencadeariam os conflitos sociais, compreendidos como lutas por reconhecimento, dado que o descontentamento social está associado a não confirmação social de determinados aspectos da personalidade dos indivíduos, contrariando assim suas expectativas prévias.

Ao final do percurso da obra Luta por reconhecimento, Honneth se propõe a refletir as condições intersubjetivas da integridade pessoal, ou seja, uma concepção de eticidade. O conceito de eticidade refere-se à concepção de vida boa. Entendemos que os sujeitos precisam encontrar reconhecimento numa sociedade moderna como seres tanto autônomos quanto individualizados. Por isso, o conceito de eticidade deve conter "todos os pressupostos intersubjetivos que hoje precisam estar preenchidos para que os sujeitos se possam saber protegidos nas condições de sua autorrealização" (HONNETH, 2003, p. 270).

A teoria do reconhecimento está na linha de uma normatividade, ou seja, partilha por interesses de normas universais que devem proporcionar ao indivíduo sua autorrealização. Por isso, Honneth entende em sua teoria do reconhecimento intersubjetivo: "está inscrita na experiência do amor a possibilidade da autoconfiança, na experiência do reconhecimento jurídico, a da autorrespeito e, por fim, na experiência da solidariedade, a da autoestima" (HONNETH, 2003, p. 272).

\section{Teologia da Libertação (TdL)}

Após apresentação, em linhas gerais, da teoria do reconhecimento de Axel Honneth recorremos à Teologia da Libertação, buscando inspiração conceitual e aplicação prática na produção do direito. O que é Teologia da Libertação? Quem é o seu interlocutor? Qual o seu método? A noção de teologia da libertação nasce com Gustavo Gutiérrez em 1968. Sua gênese 
está na intuição bíblica e teológica voltada à realidade social latino-americana (ARDUINI, 1986, p.12). O fundamento da TdL é o Evangelho.

A teologia da libertação é “expressão viva de uma experiência de fé libertadora. Ela não traduz uma reflexão deslocada, mas surge sempre num segundo momento, enquanto expressão articulada de um processo histórico marcado pela pobreza, esperança e busca libertadora" (TEIXEIRA, 2014, p.31). A TdL apresenta-se como mediação necessária para a ruptura das condições sociais que marginalizam e oprimem os segmentos pobres do continente.

\begin{abstract}
A busca da libertação do subcontinente vai mais longe que a superação da dependência econômica, social e política. Consiste, mais profundamente, em ver o devir da humanidade como um processo de emancipação do homem ao longo da história, orientado para uma sociedade qualitativamente diferente, na qual se sinta o homem livre de toda servidão, seja o artífice de seu próprio destino (GUTIÉRREZ, 1975, p.76).
\end{abstract}

A reflexão da TdL nasce intimamente articulada com a afirmação e crescimento dos movimentos sociais e populares de libertação dos anos 1960, de majoritária inspiração socialista (TEIXEIRA, 2014, p.33). Situa-se neste contexto, o que podemos denominar de irrupção dos pobres. "Os pobres têm sido, e são, na verdade, os grandes ausentes da cena histórica da humanidade [...] A pobreza é uma situação desumana e injusta, de rostos diversos" (GUTIÉRREZ, 2013, p.200-204). O pobre oprimido e não reconhecido é o interlocutor da TdL.

A TdL fez opção preferencial pelos pobres que se encontram destituídos de voz e direitos no espaço social. O pobre é o não-homem no sentido sociológico e não ontológico. $\mathrm{O}$ mundo dos pobres apresenta como a realidade insignificante no contexto social. "A pobreza significa morte prematura e injusta; morte física e cultural, na medida em que carecem dos meios necessários para viver como o exige sua dignidade humana ou são marginalizados por outras situações pessoais" (GUTIÉRREZ, 2013, p.2012). A TdL é uma práxis libertadora e transformadora do mundo. A TdL fez "a opção preferencial pelos pobres e pelas pessoas privadas da sua dignidade humana. A opção pelos pobres não exclui os ricos” (MÜLLER, 2014, p.42). Gustavo Gutiérrez e Gerhard Ludwig Müller afirmam que "o pobre deve ser preferido não porque seja necessariamente melhor que outros, a partir do ponto de vista moral ou religioso, mas porque Deus é Deus" (MÜLLER; GUTIÉRREZ, 2014, p. 118).

Teorias do Direito e Realismo Jurídico| e-ISSN: 2525-9644 | Brasília | v. 3 | n. 1 | p. 63 - 83 | Jan/Jun. 2017. 
A TdL traz em si três objetivos: (1) libertar o discurso teológico de um discurso distante da realidade do pobre e oprimido; (2) libertar o pobre de sua realidade de opressão econômica, social e política; (3) libertar o ser humano do pecado pessoal e social, em vista, da redenção. A TdL para cumprir a sua função social e religiosa adotou o método "Ver-Julgar-Agir".

O método constitui-se em três mediações: sócio-análítica $(M A S)$, hermenêutica $(M H) \mathrm{e}$ teoria-práxis (MTP). A mediação sócio-analítica (BOFF, 1978, p.37-129) corresponde ao primeiro momento do método: VER a realidade. O conhecimento da realidade é feito por meio das ciências sociais e humanas. Busca-se conhecer o que seja a opressão e a pobreza e quais são suas causas.

A mediação Hermenêutica (BOFF, 1978, p.133-271) corresponde ao momento do JULGAR a realidade à luz da Palavra de Deus, conforme a salvação ou a perdição do ser humano. Aqui se dá o processo da construção do discurso teológico. Esse segundo nível está dividido em três partes: profético (julgamento conforme a vontade de Deus); Tradição da fé (julga se suas categorias de fé são legitimadoras do status quo de opressão e dominação da alteridade); Leitura teológica de toda práxis humana (interessa pelo agir humano, ou seja, a práxis da justiça é afirmação de Deus e a injustiça sua negação) - (BOFF, 1979, p.17-18). "Privilegiam-se também o estudo e o uso da doutrina social da Igreja com o objetivo de melhor compreender a realidade e escutar uma palavra magisterial a respeito da matéria investigada" (BOMBONATTO, 2004, p.89).

A mediação teoria-práxis (BOFF, 1978, p.273-375) que corresponde ao momento do AGIR. O objetivo é romper todas as fronteiras do assistencialismo. Busca-se alcançar a libertação integral do ser humano que se encontra marginalizado e oprimido. A Igreja não deve assumir a dimensão de partido político ou ter que resolver os problemas de ordem econômica, mas ser a testemunha do Reino de Deus na história com todas as pessoas que sofrem das misérias espirituais e corporais. É o agir a favor do reconhecimento integral do ser humano em todas as suas dimensões.

\section{Direito: reconhecimento e libertação}

A partir da TdR de Axel Honneth e da TdL propomos a visão do direito como reconhecimento e libertação. Formamos uma teoria abrangente do direito - teoria e práxis (TRIVISONNO, 2015, p. 01). Apresentamos uma teoria do direito: reconhecimento e 
libertação; e, propomos uma práxis: o método "Ver-Julgar-Agir". O direito enquanto reconhecimento visa possibilitar ao ser humano o reconhecimento nas esferas do amor, do direito e da solidariedade. Reconhecer a alteridade por meio do cuidado afetivo, incluir o outro na sociedade por meio da normatização fundada no ordenamento jurídico, valorizar a alteridade em suas capacidades e valores na comunidade ética.

O direito como reconhecimento nas três relações de reconhecimento desenvolve no sujeito a autoconfiança, o autorrespeito e a autoestima. O direito integra o sujeito na totalidade da existência e da sociedade. O campo da juridicidade possui uma dimensão de humanização do ser humano e suas relações sociais. O direito torna-se lócus do reconhecimento intersubjetivo. É a mediação da formação da identidade pessoal e social do sujeito.

O direito como libertação visa libertar em primeiro de lugar, o discurso jurídico mecanicista e logicista. Em segundo lugar, libertar o ser humano de todas as opressões e alienações em que se encontra no âmbito social. Na linguagem jurídica, poderíamos afirmar que libertação é a inserção do sujeito no âmbito da sociedade, tendo seus direitos fundamentais e sociais reconhecidos. A libertação jurídica do sujeito é a passagem do não reconhecimento ao reconhecimento intersubjetivo. É tornar-se cidadão por meio de seus direitos políticos, civis e sociais.

A aplicação do conceito de direito como reconhecimento e libertação ocorre por meio do "Ver-Julgar-Agir". Primeiramente, é preciso averiguar a realidade na qual o sujeito se encontra no contexto da sociedade. Nessa primeira fase, mediação sócio-analítica, o direito apropria-se do apoio das ciências sociais e humanas. O direito vai ao encontro do indivíduo e perscruta sua condição humana e social. Verificam-se os conflitos. É conhecer o cenário e os sujeitos envolvidos. É tirar a fotografia da situação dos sujeitos envolvidos e a condição em que se encontram.

Após ver a realidade, transfere-se para a segunda fase, ou seja, mediação hermenêutica. É o momento de julgar a realidade do sujeito à luz do direito. Busca-se analisar a fotografia da realidade. É interpretação da lei em vista da verdade e da justiça. Na terceira fase do método, mediação teoria-práxis, é o momento de agir para que o conflito social ou a realidade de não 
reconhecimento do sujeito seja superado do contexto social. É o agir em vista da realidade não reconhecimento presente na fotografia da realidade.

No quadro abaixo sintetizamos, a noção de direito como reconhecimento e libertação:

\begin{tabular}{|c|c|c|}
\hline $\begin{array}{c}\text { Relações de } \\
\text { Reconhecimento }\end{array}$ & $\begin{array}{c}\text { Teologia da } \\
\text { Libertação/método }\end{array}$ & Direito do Reconhecimento e da Libertação \\
\hline Amor & VER & $\begin{array}{c}\text { Ver a realidade do sujeito - o cuidado } \\
\text { afetivo/conhecer a situação em que se encontra } \\
\text { o indivíduo. }\end{array}$ \\
\hline Direito & JULGAR & $\begin{array}{c}\text { Julgar a realidade do sujeito - avaliação jurídica } \\
\text { das condições do indivíduo. }\end{array}$ \\
\hline Solidariedade & AGIR & $\begin{array}{c}\text { Agir na realidade do sujeito - transformação de } \\
\text { exclusão e marginalização - a formação do } \\
\text { cidadão }\end{array}$ \\
\hline
\end{tabular}

O direito como reconhecimento e libertação é mediação para efetivação da justiça social para superação das desigualdades sociais e o desenvolvimento humano e social. O direito possui a efetividade de contribuir para amenizar e transformar a realidade miserável e de opressões psíquicas e físicas que o sujeito enfrenta em sua existência. O direito é o caminho que implica o reconhecimento nas relações de amor, direito e solidariedade. É libertação de suas opressões.

\section{Considerações finais}

Após o caminho percorrido, sabemos que a proposta do direito como reconhecimento e libertação é a gênese de um primeiro ensaio que merece análises mais profundas para efetivar como teoria e práxis. A riqueza na produção do direito está na diversidade de métodos que foram elaborados até o presente momento, como caminhos teóricos e práticos na produção e efetivação do direito.

O nosso objetivo não visa destituir os métodos que foram construídos, mas apresentar uma possibilidade de enxergar o direito como movimento dialético de humanização, reconhecendo e libertando os indivíduos de seus conflitos e exclusões sociais. O direito é dinâmico e necessita de um método e de uma metodologia para responder à responsabilidade de Ciência Social Aplicada na resolução de conflitos sociais.

Compreendemos que a teoria do reconhecimento de Axel Honneth e o método da Teologia da Libertação em Gustavo Gutiérrez possibilitam a elaboração de uma teoria do direito e sua práxis. O direito é reconhecimento do sujeito nas esferas do amor, direito e solidariedade. 
É libertação do não reconhecimento do sujeito que se encontram nas situações de maus-tratos, exclusão social e degradação social de seu ser na comunidade de valores.

A teoria do direito consiste no reconhecimento como forma de constituição da identidade pessoal e social. Quando o indivíduo é reconhecimento sua existência se efetiva na dignidade. Quando o sujeito é libertado de suas opressões sua existência torna-se integrada no contexto social, respeitada como valor positivo. Ser reconhecido e libertado e experimentar a justiça social e o direito de ser e viver.

O direito como libertação se efetiva por meio do método "Ver-Julgar-Agir". O direito sai de si e vai ao encontro da alteridade. Após ver a realidade, a situação do sujeito é julgada à luz do Direito. Analisa se a vida do sujeito está em conformidade com o direito positivado. Caso contrário, deve realizar a correção material (moral) do caso em questão. Por fim, o agir/práxis é transformar a realidade do sujeito que está experimentando a situação de não reconhecimento. Em outras palavras, é aplicação do direito.

Acreditamos que a noção de direito como reconhecimento e libertação revela-se como movimento dialético do método jurídico e de humanização do direito em prol da construção de uma sociedade justa, livre e solidária.

\section{Referências}

AFONSO, Elza Maria Miranda. O positivismo na epistemologia jurídica de Hans Kelsen. Belo Horizonte: Editora UFMG, 1984.

Passos da teoria de Kelsen rumo á construção da Teoria do Direito. In: OLIVEIRA, Júlio Aguiar de; TRIVISONNO, Alexandre Travessoni Gomes. Hans Kelsen: teoria jurídica e política. Rio de janeiro: Forense Universitária, 2013.

ALLAND, Denis; RIALS, Stéphane. Dicionário da cultura jurídica. Tradução de Ivone Castilho Benedetti. São Paulo: Martins Fontes, 2012.

ARDUINI, Juvenal. Horizontes de Esperança: Teologia da Libertação. São Paulo: Paulinas, 1986.

ASSY, Bethânia; FERES JÚNIOR, João. Reconhecimento. In: BARRETTO, Vicente de Paulo (coord.). Dicionário de filosofia do direito. São Leopoldo: Unisinos; Rio de Janeiro: Renovar, 2006.

Teorias do Direito e Realismo Jurídico| e-ISSN: 2525-9644 | Brasília | v. 3 | n. 1 | p. 63 - 83 | Jan/Jun. 2017. 
BARZOTTO, Luis Fernando. O Positivismo Jurídico Contemporâneo - uma introdução a Kelsen, Ross e Hart. 2. ed. Porto Alegre: Livraria do Advogado Editora, 2007.

BODENHEIMER, Egar. Ciência do Direito: filosofias e metodologias jurídicas. Rio de Janeiro: Forense, 1966.

BOFF, Clodovis. Teologia e prática: teologia do político e suas mediações. Petrópolis: Vozes, 1978.

BOFF. Leonardo; BOFF. Clodovis. Da Libertação: o sentido teológico das libertações sóciohistóricas. Petrópolis: Vozes, 1979.

GOMES, Alexandre Travessoni. O fundamento de validade do direito - Kant e Kelsen. 2. Ed., atual. e ampl. Belo Horizonte: Mandamentos, 2004.

GONTIJO, Lucas de Alvarenga. Filosofia do Direito: metodologia jurídica, teoria da argumentação e guinada linguístico-pragmática. Belo Horizonte: Arraes Editores, 2011.

GUTIÉRREZ, Gustavo. Teologia da libertação. Petrópolis: Vozes, 1975.

A teologia latino-americana: trajetória e perspectivas. In: BRIGHENTI, Agenor; HERMANO, Rosario (orgs.). A Teologia da Libertação em prospectiva. São Paulo: Paulus/Paulinas, 2013.

HEIDEGGER, Martin. Os Conceitos Fundamentais da Metafísica: Mundo - Finitude Solidão. Trad. Marco Antônio Casanova. Rio de Janeiro: Forense Universitária, 2003.

HONNETH, Axel. Luta por reconhecimento - a gramática moral dos conflitos sociais. São Paulo: Ed. 34, 2003, p. 215.

KELSEN, Hans. Teoria Pura do direito. São Paulo: Martins Fontes, 1985.

MÜLLER, Gerhard Ludwig; GUTIÉRREZ, Gustavo. Ao lado dos pobres - Teologia da Libertação. São Paulo: Paulinas, 2014.

PEREIRA, Tiago Porto. Desrespeito e patologias sociais na Filosofia de Axel Honneth. Problemata: Revista Internacional de Filosofia. v. 7. n. 1, p. 169-191, 2016.

SAAVEDRA, Giovani Agotini; SOBOTTAKA, Emil Albert. Introdução à teoria do reconhecimento de Axel Honneth. Revista Civitas, Porto Alegre, v.8, n. 1, jan/abr. 2008.

SILVA, Cristiane Freitas da. Pobreza e desigualdade no brasil: uma análise da contradição capitalista. VII Congresso Português de Sociologia, 12 a 22 de junho de 2012. Universidade do Porto. 
TRIVISONNO, Alexandre Travessoni Gomes. A teoria discursiva do direito de Alexy e as duas questões fundamentais da filosofia do direito. In: ROBERT, Alex. Teoria discursiva do direito. Organização, tradução e estudo introdutório de Alexandre Travessoni Gomes Trivisonno. 2. ed. Rio de Janeiro: Forense Universitária, 2015.

WERLE, D. L. Lutas por reconhecimento e justificação da normatividade. (Rawls,Taylor e Habermas). Tese apresentada no Departamento de Filosofia da USP para a obtenção do título de Doutor. São Paulo, 2004. 